\title{
The demand for military spending in Latin American countries
}

\author{
Christos Kollias $^{1 *}$, Suzanna Maria Paleologou ${ }^{2}$, Panayiotis Tzeremes ${ }^{1}$ and Nickolaos Tzeremes ${ }^{1}$
}

\author{
*Correspondence: \\ kollias@uth.gr \\ ${ }^{1}$ Laboratory of Economic \\ Policy \& Strategic Planning, \\ Department of Economics, \\ University of Thessaly, Volos, \\ Greece \\ Full list of author information \\ is available at the end of the \\ article
}

\begin{abstract}
The allocation of resources to defence and national security is influenced by several factors, both domestic and external. Empirical findings suggest that military spending is determined by economic, strategic, political, and security factors. Studies that estimate demand functions for such budgetary outlays focus either on individual country case studies or on groups of countries that share some similar traits and characteristics or belong to the same geopolitical region. This paper, using a panel of 12 Latin American countries and quantile regression analysis, estimates the demand for military expenditure over the 1965-2015 period. Results reported herein indicate that such spending has been driven by both domestic and external factors. The former include the economy as well as the political characteristics of the government as these are quantified by the Polity index of democracy. Intrastate conflict that has plagued many Latin American countries also emerges as a strong driving force in the allocation of resources to defence. Military spending by neighbouring countries with common borders emerges as the external strategic determinant that affects the demand for defence expenditures.
\end{abstract}

Keywords: Latin America, Military spending, Quantile regression

JEL classification: H56, C21, C23

\section{Introduction}

Military spending is the monetary quantification of the resources allocated to national defence. It represents the costs of the inputs that go into the production of military capabilities and strength. As shown by the seminal contributions of Smith (1980, 1989), a cohort of factors determine the level of the resources allocated to the defence sector. They include external as well as domestic security considerations, economic constraints, strategic aspirations, and the ideological and political orientation of the incumbent government (inter alia: Pamp and Thurner 2017; Bove and Brauner 2016; Douch and Solomon 2016; Dunne et al. 2003, 2008).

External security determinants of such spending take the form of actual or potential threats emanating from other states thus generating the need to produce credible defence capabilities to deter them. Ceteris paribus, during periods of tension and even more so during military conflict the allocation of resources to defence increases. The reverse effect is the case when international or regional tensions recede (inter alia: Cavatorta and Smith 2017; Sandler and George 2016; Nordhaus et al. 2012; Solarin 2017). 
Given that armed forces are often used to maintain internal law and order, internal security determinants such as civil war, insurgencies, civil strife often affect the levels of such spending. To this, one may also add the political inclinations of the incumbent government and hence its defence and broader policy traits (inter alia: Kauder and Potrafke 2016; Albalate et al. 2012; Bove and Nisticò 2014; Yildirim and Sezgin 2005). Clearly, the inevitable budgetary constraint that influences the level of public expenditures, also affects the annual defence budget and the resources allocated to the military (Christie 2017).

As noted by Dunne et al. (2003), case studies of individual countries or studies of groups of relatively homogeneous countries that belong to the same geopolitical region offer a suitable context within which the determinants of military spending can be examined empirically. Within the strand of this growing body of literature, this paper sets out to investigate the factors that influence the yearly budgetary allocations to defence by Latin American countries. This is a theme that has been addressed in the past for individual Latin American countries by studies such as Looney and Fredericksen (1986, 1988) for Argentina, Klein (2004) for Peru, Peláez (2007) for Uruguay, Ramos (2004) for Mexico. However, to the best of our knowledge, no previous study has probed into the determinants of defence expenditures for Latin American countries as a group of states that belong to the same geopolitical region.

A further contribution of this paper is the fact that, in the empirical investigation that follows, we use SIPRI's new consistent database on military spending (Perlo-Freeman 2017; Perlo-Freeman and Sköns 2016). In some cases, the time-series of the dataset extend back to 1949 and hence offer the opportunity for researchers to obtain more robust and reliable inferences over a longer time horizon as recent studies have done addressing various aspects of military spending (inter alia: Dunne and Tian 2016; Kollias et al. 2017; Malizard 2016; d'Agostino et al. 2017).

To address the issue at hand, we use a panel of 12 Latin American countries: Dominican Republic, El Salvador, Guatemala, Mexico, Argentina, Bolivia, Brazil, Chile, Colombia, Ecuador, Peru and Venezuela. Quantile regression analysis for the period 1965-2015 is used to estimate the demand function for military expenditure. Data availability considerations and the inevitable compromise between $\mathrm{T}$ and $\mathrm{N}$, dictated the choice of the 12 countries.

The paper is structured as follows. The section that follows contains a brief discussion on the determinants of military spending. Section three is a descriptive and comparative presentation of the data used for the 12 Latin American countries that make-up the sample. The empirical methodology is presented in section four and the findings from the quantile regressions estimations are presented and discussed in section five. Finally, section six concludes the paper.

\section{The determinants of defence expenditures: a primer}

As observed by Abdelfattah et al. (2014), if one attempts to summarise the literature that focuses on the determinants of military spending, two broad strands of approaches can be identified in the empirical studies that probe into this subject. One group of papers employs Richardsonian type arms race modelling. It focuses on the dynamics of the interaction between states that are either engaged in conflict or, have strong antagonistic 
relations with the potential to escalate to an armed confrontation. The USA-USSR dyad during the Cold War era is perhaps the most representative example of such a case where Richardson (1960) type models are used to explain the dynamics of defence expenditures in an arms race context. A second group of studies of the determinants of defence outlays consists of a range of models of the demand for military spending that have been developed and empirically tested drawing on different approaches to the decision-making process and the influence exerted by a cohort of strategic, security, political and economic factors (Smith 1989, 1995; Paleologou 2015).

In applied studies that estimate demand functions, military expenditures are invariably expressed in shares of GDP while political and strategic variables that can affect such public outlays are quantified through various indices (inter alia: Bove and Brauner 2016; Kauder and Potrafke 2016; Dunne et al. 2003, 2008; Albalate et al. 2012; Dunne and Perlo-Freeman 2003). For example, to allow for the possible effects that the ideological and political traits of the government exert on foreign and defence policy and hence on defence spending, indices that quantify the regime type can be introduced in the estimations.

One such index, that is also used in the quantile regressions estimations that follow, is the Composite Polity 2 index from the Polity IV project. As Papaioannou and Siourounis (2008) note, this index is widely considered to be the most comprehensive one, quantifying key facets of the regime type and the quality of democratic rule, or the absence of it. The Polity Index, takes values from -10 for autocracies to +10 for full democracies. Intuitively, one would expect less democratic governments to be more inclined to spend more on the armed forces since they can also be used for internal security purposes quashing opposition and dissident political and social movements. Indeed, as noted by Kollias et al. (2017), a particular feature of Latin American countries is the role that the armed forces have historically played in domestic politics (inter alia: Catoggio 2011; Frantz and Geddes 2016; Biglaiser 2002).

The effect exerted on the demand for defence spending by the geopolitical circumstances of the region, can be captured via the military strength of other neighbouring states as this is reflected in their respective military expenditures. If tensions and frictions are a characteristic of the area, then, ceteris paribus, one would expect that an upward pressure will be the effect on the defence budgets of the countries that make up the region (Markowski et al. 2017). The reverse is the case during periods when tensions recede. The external environment that affects the levels of resources allocated to defence is termed by Rosh (1988) as a country's Security Web. The Web includes the neighbouring states and other international powers that can potentially affect national security and hence defence spending while dummy variables can capture events such an armed confrontation and/or an insurgency. Invariably, national defence is cited as the typical example of a public good. Thus, population is also included in the estimated models to allow for possible public good effects.

Variables encapsulating the openness of the economy are often included in the empirical estimations (inter alia: Nikolaidou 2008; Dunne et al. 2003). The sum of exports and imports of goods and services measured as a share of GDP is the variable most preferred to quantify openness. The effect of openness on military spending is ambiguous. For example, Rosh (1988) postulates that countries highly integrated in the global economy 


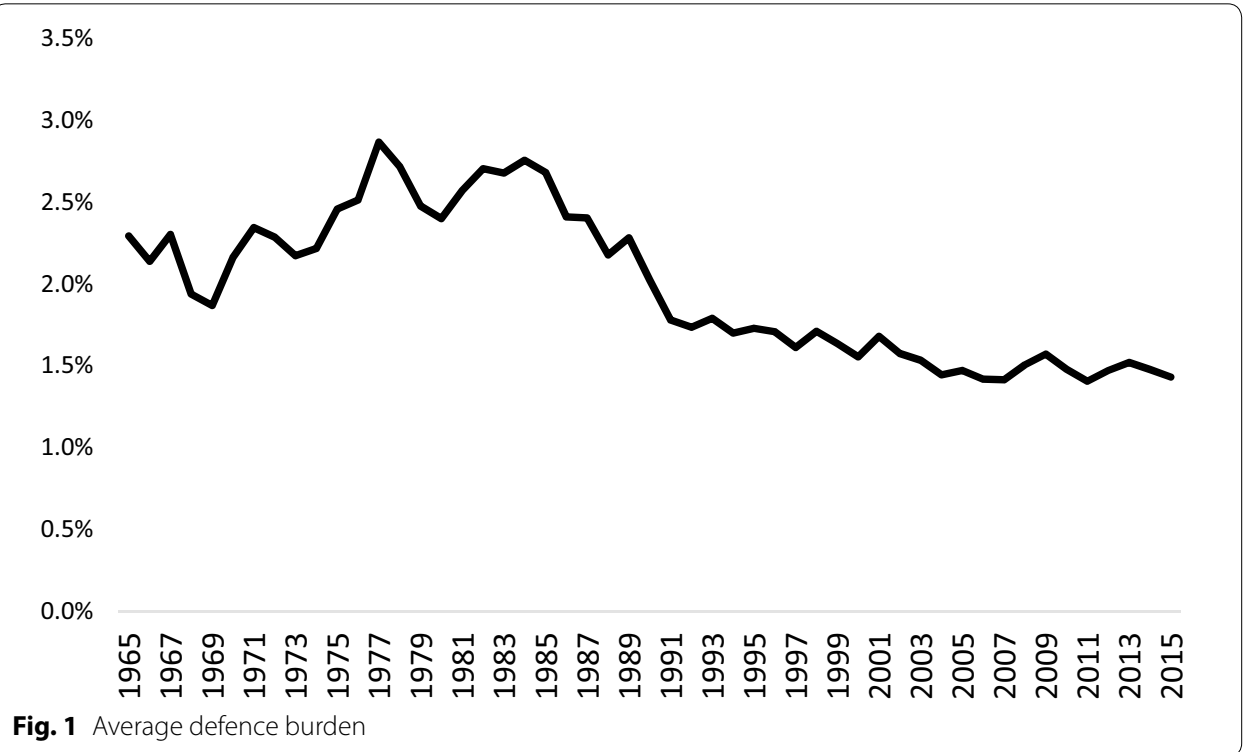

probably find it easier to access arms markets and finance for arms procurement. On the other hand, however, it has been shown that international trade has a peace promoting influence both between belligerent countries as well as within countries (Seitz et al. 2015; Huang and Throsby 2011; Kollias and Paleologou 2017). The openness of the economy and increased access and participation of countries in international trade is a factor that reduces the probability of conflict (Huang and Throsby 2011) whereas the benefits from increased peacefulness also take the form of reductions in defence spending with the concomitant welfare effects (Seitz et al. 2015).

Finally, in the case of the Latin American sample of countries examined here, a further driver of military spending could be the fight against organized crime such as drug cartels. As noted in a number of studies (Blanco and Ruiz 2013; Soares and Naritomi 2010; Di Tella et al. 2010), Latin America is a region with fairly intense organized crime activity and the armed forces are often used in thwarting organized criminal networks.

\section{The data: a descriptive and comparative presentation}

We start the descriptive presentation of the data by taking a bird's eye view of how the entire sample of the 12 Latin American countries has fared in terms of the defence burden (military spending as a share of GDP) during the period in question, i.e., 19652015. ${ }^{1}$ As can be seen in Fig. 1, two distinct trends are identifiable. A generally upward one up to the mid-1980s and then a steady downward trend that has leveled off in recent years around the $1.5 \%$ level in terms of defence burden. This broad picture is roughly similar with the trend of the average defence burden globally (Arvanitidis and Kollias 2016). In general, the Latin American countries of the sample seem to be converging towards lower levels of defence burdens albeit strictly speaking such an inference requires formal analysis that does not fall within the scope of this paper.

${ }^{1}$ Military spending data drawn from Stockholm International Peace Research Institute (SIPRI) https://www.sipri .org/databases/milex. 
Table 1 The defence burden (\%)

\begin{tabular}{llll}
\hline & Average & Max & Min \\
\hline Dominican Republic & 1.3 & 4.2 & 0.3 \\
El Salvador & 1.7 & 6.6 & 0.6 \\
Guatemala & 1.1 & 2.2 & 0.4 \\
Mexico & 0.6 & 0.7 & 0.4 \\
Argentina & 1.8 & 4.7 & 0.8 \\
Bolivia & 2.1 & 3.9 & 1.3 \\
Brazil & 1.8 & 3.4 & 1.1 \\
Chile & 4.0 & 8.9 & 1.9 \\
Colombia & 2.6 & 4.4 & 1.4 \\
Ecuador & 2.1 & 3.1 & 1.5 \\
Peru & 2.9 & 8.2 & 1.1 \\
Venezuela & 1.8 & 3.0 & 0.6 \\
\hline
\end{tabular}

A closer, country-level inspection reveals noteworthy differences between the 12 countries as can be observed from Table 1. In terms of military spending as a share of GDP, Chile emerges as the country with the highest average (4\%) during the period examined here and Mexico with the lowest $(0.6 \%)$. Chile along with Peru are the two countries with the highest maximum value: $8.9 \%$ in 1982 and 8.2\% in 1977, respectively. As discussed in the previous section, a number of factors both internal and external influence such spending. Apart from the omnipresent budgetary constraint, determinants of military expenditures include intrastate and interstate conflict, the ideological and political traits of the incumbent political party.

Latin American countries have experience significant levels of often protracted conflict, mostly domestic in the form of insurgencies and civil war. Limiting the discussion to the 12 countries that make up the sample, a brief historical summary of both interstate and intrastate conflict is shown in Table 2. Peru and Ecuador are two of the 12 countries in the sample that have engaged in armed confrontation with each other on

Table 2 Conflict and military rule

\begin{tabular}{ll}
\hline Interstate conflict & 1981: Peru \& Ecuador, Paquisha incident \\
& 1982: Argentina \& UK, Falklands War \\
& 1995: Peru \& Ecuador, Cenepa War \\
& 1980-: Peru, Shining Path \\
& 1975-1976: Argentina, Operativo Independencia \\
& 1976-1983: Argentina, Dirty War \\
& 1964-: Colombia, FARC \& ELN \\
& 1960-1996: Guatemala, Civil War \\
& $1979-1992:$ El Salvador, Civil War \\
& $1964-1985:$ Brazil \\
Military rule & $1966-1973:$ Argentina \\
& $1968-1980:$ Peru \\
& $1970-1982:$ Bolivia \\
& $1973-1990:$ Chile \\
& $1976-1983:$ Argentina
\end{tabular}


two occasions during the period examined here: in 1981 and 1995. Argentina on the other hand is the only one that had an armed confrontation with a state outside Latin America: the UK in 1982 (Table 2). Intrastate is the dominant form of conflict that has afflicted the 12 Latin American countries of the sample. Peru, Colombia, Guatemala, El Salvador are countries that have experienced protracted internal conflict.

For example, in the case of Peru the second highest average defence burden (Table 1) can partially be attributed to the long-running territorial disputes with Ecuador as well as domestic conflict associated with terrorist activity by Sendero Luminoso and the Tupac Amaru Revolutionary Movement (Klein 2004). In a similar vein, insurgency and the concomitant armed confrontation between government forces and paramilitaries such as FARC and ELN can be cited as possible explanatory factors of the comparatively higher defence burden of Colombia (Vargas 2012).

As noted by Kollias et al. (2017), a particular feature of Latin American countries is the role that the armed forces have historically played in the domestic political scene of many Latin American countries. During the period in question, Argentina, Bolivia, Brazil, Chile and Peru are five countries out of the 12 included in the sample that have known overt military rule (Table 2). Kollias et al. (2017) observe that the overt or indirect involvement of the military in the domestic political life of almost all countries was for decades an endemic characteristic of Latin America and its legacy has left an indelible imprint in the region's history. However, as many have pointed out, the dominant presence and central role of the military in Latin American politics, either in the form of direct military rule or military coups, rapidly withered away towards the late 1980s (inter alia: Norden 1996; Dix 1994).

The authoritarian regime past of the region is reflected in the average values of Polity 2 Index ${ }^{2}$ mentioned in the previous section. As can be seen in Fig. 2, on average the Polity 2 index score of the 12 countries in the sample was negative up to the end of the 1970s. Since then, a fairly rapid improvement is recorded as the 12 countries progressed towards more democratic political regimes during the 1980s. Colombia is the country that scores the best average in the index's scale of -10 to +10 during the period under examination here, followed by Ecuador and Dominican Republic (Table 3). Overall, with the exception of Venezuela, the sample countries exhibit a steady pace towards more democratic rule. As already mentioned, the Polity 2 index will be introduced in the empirical estimations.

As the case is for all types of public expenditures, military spending is also influenced by economic factors. In the relevant literature on the demand for military expenditure, the growth rate of the economy is invariably included in empirical studies while the openness of the economy is captured by the share of exports and imports to GDP (inter alia: Pamp and Thurner 2017; Bove and Brauner 2016; Abdelfattah et al. 2014). Table 4 offers a comparative summary in terms of these two macroeconomic variables for the sample of the 12 countries. Data on the growth rate of the economy and the indicator are drawn from the World Bank's World Development Indicators database. ${ }^{3}$

\footnotetext{
${ }^{2}$ Data source: http://www.systemicpeace.org/polityproject.html.

${ }^{3}$ https://data.worldbank.org/indicator.
} 


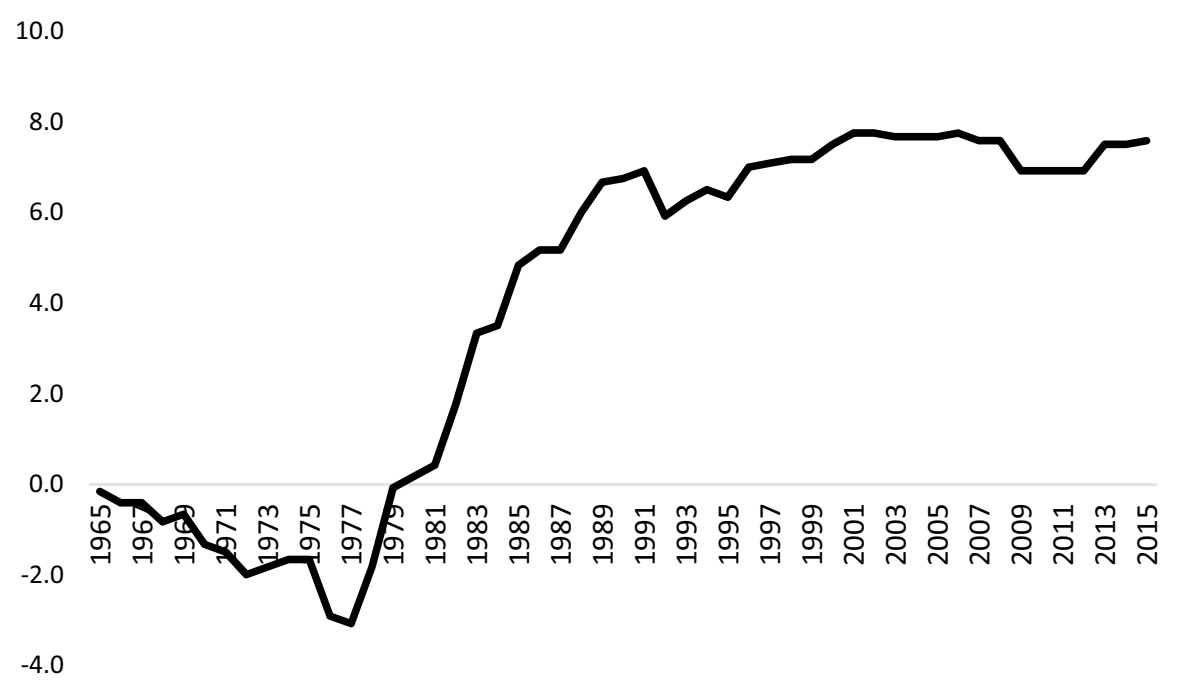

Fig. 2 Average Polity index score

Table 3 Polity index scores

\begin{tabular}{llcc}
\hline & Average & Max & Min \\
\hline Dominican Republic & 4.5 & 8 & -3 \\
El Salvador & 4.1 & 8 & -6 \\
Guatemala & 2.9 & 8 & -7 \\
Mexico & 1.0 & 8 & -6 \\
Argentina & 2.9 & 9 & -9 \\
Bolivia & 3.7 & 9 & -7 \\
Brazil & 2.4 & 8 & -9 \\
Chile & 3.7 & 10 & -7 \\
Colombia & 7.5 & 9 & 7 \\
Ecuador & 4.8 & 9 & -5 \\
Peru & 3.5 & 9 & -7 \\
Venezuela & 6.8 & 9 & -3 \\
\hline
\end{tabular}

In terms of average growth performance during the period examined here, the Dominican Republic emerges as the country with the highest annual average of 5.2\%, followed by Brazil, Chile and Colombia with $4.3 \%$ average annual growth rate each. El Salvador, Argentina and Venezuela are the countries with the lowest annual averages (2.5\%, 2.7\%, and $2.7 \%$, respectively). In terms of the economic openness indicator El Salvador and the Dominican Republic lead the group. As a percentage of GDP, the sum of exports and imports during the period under examination averaged $61 \%$ and $60.4 \%$, respectively. Brazil and Argentina are the two countries with the lowest annual averages in terms of this indicator: $19 \%$ and $20.4 \%$ respectively. 
Table 4 Growth rates and openness

\begin{tabular}{|c|c|c|c|c|c|c|}
\hline & \multicolumn{3}{|c|}{ GDP growth rate (\%) } & \multicolumn{3}{|c|}{$\begin{array}{l}\text { Openness (imports + exports as } \% \\
\text { of GDP) }\end{array}$} \\
\hline & Average & Max & Min & Average & Max & Min \\
\hline Dominican Republic & 5.2 & 18.2 & -12.5 & 60.4 & 86.5 & 32.7 \\
\hline El Salvador & 2.5 & 7.5 & -11.8 & 61.0 & 76.6 & 36.9 \\
\hline Guatemala & 3.9 & 9.5 & -3.5 & 45.4 & 69.5 & 24.9 \\
\hline Mexico & 4.1 & 11.9 & -5.8 & 35.8 & 72.8 & 15.9 \\
\hline Argentina & 2.7 & 12.7 & -10.9 & 20.4 & 41.8 & 10.3 \\
\hline Bolivia & 3.1 & 8.0 & -12.2 & 53.1 & 85.3 & 31.3 \\
\hline Brazil & 4.3 & 14.0 & -4.4 & 19.0 & 29.7 & 9.1 \\
\hline Chile & 4.3 & 12.3 & -11.4 & 50.6 & 81.0 & 23.1 \\
\hline Colombia & 4.3 & 8.5 & -4.2 & 31.6 & 39.0 & 21.8 \\
\hline Ecuador & 4.0 & 14.0 & -4.7 & 41.6 & 68.1 & 19.3 \\
\hline Peru & 3.8 & 12.3 & -12.3 & 38.3 & 58.4 & 22.5 \\
\hline Venezuela & 2.7 & 18.3 & -8.9 & 47.6 & 60.1 & 30.7 \\
\hline
\end{tabular}

\section{The methodology: an epigrammatic presentation}

On the basis of the forgone discussion on the demand for military expenditure modelling issues and in line with previous studies such as Dunne et al. $(2003,2008)$, Kauder and Potrafke (2016), Albalate et al. (2012) we specify the linear regression model:

$$
\mathrm{MGDP}_{i}=\beta_{0}+\beta_{1} \mathrm{GDP}+\beta_{2} \mathrm{POP}+\beta_{3} \mathrm{TRD}+\beta_{4} \mathrm{POLITY}+\beta_{5} \mathrm{INTER}+\beta_{6} \mathrm{INTRA}+\beta_{7} \mathrm{MN}+\varepsilon_{i}
$$

In specification (1), the principal model to be estimated, the response variable MGDP is the military spending expressed as a share of GDP; GDP is the growth rate of the gross domestic product; POP is the population variable ${ }^{4}$; TRD is the economy openness variable, i.e., the sum of exports and imports as a share of GDP; POLITY is the index that quantifies the regime type taking values in the $-10,+10$ scale; INTER and INTRA are dummies for interstate and intrastate conflict, respectively (Table 2); MN is the Security Web variable that is the average military spending of the neighbouring countries with common borders. With the exception of POLITY, INTER and INTRA, all variables are log transformed.

Finally, as already mentioned in the previous section, it was decided to include a further explanatory variable in the econometric analysis that follows. As Soares and Naritomi (2010) observe, Latin America has been traditionally seen as a particularly violent region of the world in terms of criminal activity. Often, the armed forces are used in the fight against organized crime in general and drug producing syndicates in particular. Indeed, Latin America has one of the highest crime rates in the world, and deaths due to violence is a much more common occurrence in Latin America than in any other region

\footnotetext{
${ }^{4}$ Data drawn from the World Banks' World Development Indicators database https://data.worldbank.org/indicator.
} 
(Soares and Naritomi 2010; Blanco and Ruiz 2013; Di Tella et al. 2010). Hence, the principal model (1) was augmented with the addition of a Crime Rate variable $^{6}$ :

$$
\begin{aligned}
\operatorname{MGDP}_{i}= & \beta_{0}+\beta_{1} \text { GDP }+\beta_{2} \text { POP }+\beta_{3} \text { TRD }+\beta_{4} \text { POLITY } \\
& +\beta_{5} \text { INTER }+\beta_{6} \text { INTRA }+\beta_{7} \mathrm{MN}+\beta_{8} \text { Crime Rate }+\varepsilon_{i}
\end{aligned}
$$

In the empirical investigation that follows we apply both parametric and nonparametric analysis to enhance the robustness of our empirical findings and account for nonlinear effects. Therefore, alongside with the parametric estimation we apply the quantile regression and then the generalized additive mixed models (GAMMs). Aiming at a more comprehensive picture of all probable relationships between dependent and independent variables, Koenker and Basset (1978) proposed the quantile regression estimation methodology. Unlike the ordinary least squares methodology (OLS) which only captures the conditional mean, this technique generates estimates for every conditional quantile across the distribution of an outcome variable. Additionally, contrary to OLS models, quantile regressions are semiparametric in a manner that the assumptions of: (i) homoscedasticity, (ii) parametric distribution of the disturbance term and (iii) absence of outliers may be relaxed (Johnston and DiNardo 1997). The computational representation of the conditional quantile function is as follows:

$$
Q_{q}\left(y_{i} \mid x_{i}\right)=\alpha(q)+x_{i}^{\prime} \beta(q) \text { with } q \in(0,1)
$$

in which $y_{i}$ is the outcome variable of observation $i, x_{i}^{\prime}$ is the set of regressors corresponding to the discrete observation $i, q$ denotes the $q$ th quantile (which is defined as the value of $y$ that divides the sample in two parts: $q$ below and $1-q$ above), and the subscript $i=1,2,3, \ldots, K$ is a manifestation of individual observations. $Q_{q}\left(y_{i} \mid x_{i}\right)$ represents the $q$ th conditional quantile of $y_{i}$ given $x_{i}$. Moreover, quantile regressions categorize the data sample into high-down to low quantiles of the outcome variable in a form that differs from simple categorization. In a quantile regression, on the other hand, the classification of $(y)$ is conditional on the regressor $(x)$ (Koenker 2004). In addition, endogeneity and the possibility for reverse causation in a quantile regression can be addressed with nonparametric instrumental variables quantile regression estimators (Chernozhukov et al. 2007; Horowitz and Lee 2007). In light of the above, the following quantile regression equation was used to test the main hypotheses in this study, we set ( $q \in\{0.05,0.1,0.25,0.5,0.75,0.9,0.95\}$ ) so that the MGDP equation obtains the following form:

$$
\begin{aligned}
\operatorname{QMGDP}_{i}(q)= & \beta_{0}(q)+\beta_{1}(q) \mathrm{GDP}+\beta_{2}(q) \mathrm{POP}+\beta_{3}(q) \mathrm{TRD}+\beta_{4}(q) \mathrm{POLITY} \\
& +\beta_{5}(q) \mathrm{INTER}+\beta_{6}(q) \mathrm{INTRA}+\beta_{7}(q) \mathrm{MN}+\varepsilon_{i}
\end{aligned}
$$

and

$$
\begin{aligned}
\operatorname{QMGDP}_{i}(q)= & \beta_{0}(q)+\beta_{1}(q) \mathrm{GDP}+\beta_{2}(q) \mathrm{POP}+\beta_{3}(q) \mathrm{TRD}+\beta_{4}(q) \mathrm{POLITY} \\
& +\beta_{5}(q) \text { INTER }+\beta_{6}(q) \text { INTRA }+\beta_{7}(q) \mathrm{MN}+\beta_{8}(q) \text { Crime Rate }+\varepsilon_{i}
\end{aligned}
$$

\footnotetext{
${ }^{5}$ We thank an anonymous reviewer for this suggestion.

6 Expressed as intentional homicide rates per 100,000 population. Data are drawn from the United Nations Office on Drugs and Crime https://www.unodc.org/unodc/en/data-and-analysis/statistics/index.html. Crime data was not available for the entire period, i.e. 1965-2015 so it was decided to re-estimate only for the period for which data on homicides was available. Furthermore, due to data availability limitations such as missing/unavailable data in the time-series, model (2) was estimated for a panel of only six Latin American countries-El Salvador, Mexico, Colombia, Ecuador, Peru and Venezuela-for the period 2003-2015.
} 
As a further step, we also use generalized additive mixed models (henceforth GAMMs) to determine patterns between the covariates and MGDP. The GAMMs extend the generalized linear mixed model with a large array of tools for modelling non-linear dependencies among a response variable and one or more numeric predictors (Baayen et al. 2016). The GAMMs offer a flexible mode to build more distribution models because they fit non-linear relationships and account for correlation framework in clustered sample (Wood 2006a, b). According to Wood (2000, 2004, 2006a, b) the GAMMs can be expressed as:

$$
y_{i}=\boldsymbol{\theta} \boldsymbol{X}_{i}+w_{1 i} f_{1}\left(x_{1 i}\right)+w_{2 i} f_{2}\left(x_{2 i}\right)+w_{3 i} f_{3}\left(x_{3 i}\right)+\cdots+\boldsymbol{b} \boldsymbol{Z}_{i}+\varepsilon_{i} .
$$

$y_{i}$ indicates the dependent variable, whereas, $\boldsymbol{X}_{i}$ are the parametric component. In addition the $w_{j i}^{\prime} s$ and the $f_{j}^{\prime} s$ are the smooth functions of the estimated covariates. In particular, $w_{j i}$ 's was denoted employing the tensor product smooth and $f_{j}^{\prime} s$ was denoted employing cubic regression spline (Wood 2003). Moreover, $\boldsymbol{Z}_{i}$ indicates a row of a random effects model matrix and $\varepsilon_{i}$ is the residual error vector. As has been described by Wood (2006a, b) we apply tensor product smoothers of all the variables estimated in our model. Wood et al. (2013) suggest that the tensor smoother product is appropriate when the variables used are in different units and the relative scaling is arbitrary as the case is here given the mix of variables introduced in the estimations. The aim of such an exercise is to compare the deviance of the model fitting the (continuous) variables nonparametrically with that of the model fitting the terms linearly.

\section{The findings}

We turn now to the presentation and discussion of the results yielded from estimating (1) and (2). Starting from the principal model, Table 5 reports the OLS estimates for the effect of the above covariates on defence spending expressed as a share of GDP (MGDP) as well as the findings for the various quantiles. By and large, the resulting OLS coefficients conform to the theoretically predicted directions. The defence burden seems to be affected in a statistically significant manner by the economy (GDP), population (POP), the Security Web (MN), intrastate conflict (INTRA) and the regime type (POLITY).

Table 5 OLS and quantile regression results for the principal model (1)

\begin{tabular}{|c|c|c|c|c|c|c|c|c|c|}
\hline & \multirow{2}{*}{$\begin{array}{l}\text { OLS } \\
\text { regression } \\
\text { OLS }\end{array}$} & \multirow{2}{*}{$\begin{array}{l}\text { Fixed } \\
\text { effects } \\
\text { FE }\end{array}$} & \multicolumn{7}{|c|}{ Quantile regression } \\
\hline & & & Q0.05 & Q0.10 & Q0.25 & Q0.50 & Q0.75 & Q0.90 & Q0.95 \\
\hline Constant & $0.210^{* * *}$ & $0.189^{* * *}$ & $0.081^{* * *}$ & $0.010^{* * *}$ & $0.081^{* * *}$ & $0.011^{* * *}$ & $0.023^{* * *}$ & $0.023^{* * *}$ & $0.035^{* * *}$ \\
\hline GDP & $-0.200^{* *}$ & $-0.059^{* * *}$ & $-0.012^{* *}$ & $-0.015^{* * *}$ & -0.013 & 0.011 & 0.007 & $-0.036^{* *}$ & $-0.076^{* * *}$ \\
\hline POP & $-0.050^{* * *}$ & $-0.126^{* *}$ & $0.00^{* * *}$ & $0.00^{* * *}$ & $0.00^{* * *}$ & $0.00^{* *}$ & $0.00^{* * *}$ & $0.00^{* * *}$ & $0.00^{* * *}$ \\
\hline TRD & -0.003 & -0.016 & $-0.011^{* * *}$ & $-0.001^{* * *}$ & $-0.007^{* * *}$ & $-0.009^{* *}$ & $-0.009^{*}$ & $0.011^{* * *}$ & $0.007^{*}$ \\
\hline POLITY & $-0.300^{*}$ & $-0.206^{* *}$ & $0.048^{* * *}$ & $0.038^{* * *}$ & $0.002^{* *}$ & $0.024^{* * *}$ & -0.014 & $-0.044^{* * *}$ & $-0.002^{* * *}$ \\
\hline INTER & 0.202 & 0.165 & $0.058^{* * *}$ & $0.086^{* *}$ & 0.004 & 0.041 & -0.033 & 0.028 & 0.091 \\
\hline INTRA & $0.404^{* * *}$ & $0.313^{* *}$ & $0.094^{* * *}$ & $0.059^{* * *}$ & $0.063^{* * *}$ & $0.037^{* *}$ & $0.044^{* * *}$ & $0.035^{* * *}$ & $0.011^{* * *}$ \\
\hline $\mathrm{MN}$ & $0.103^{* * *}$ & $0.356^{* *}$ & $0.103^{* * *}$ & $0.084^{*}$ & $0.298^{* * *}$ & $0.374^{* * *}$ & 0.235 & $0.642^{* * *}$ & $0.575^{* * *}$ \\
\hline $\begin{array}{l}\text { [Pseudo- } \\
\quad] R^{2}\end{array}$ & 0.145 & 0.189 & 0.133 & 0.142 & 0.140 & 0.081 & 0.078 & 0.194 & 0.319 \\
\hline
\end{tabular}

***, ${ }^{* *}$, and ${ }^{*}$ significant at the 1,5 , and $10 \%$ levels, respectively 
Noteworthy is the statistical insignificance of the interstate dummy (INTER) vis-à-vis the positive and statistical effect exerted by intrastate conflict (INTRA).

In view of the fact that domestic conflict in the form of insurgencies and civil war is the most protracted type of conflict that has plagued the countries in the sample this is not a surprising finding given its consistency over all quantiles as will be discussed further down. A strong, positive effect is also exerted by the Security Web coefficient a finding also fairly stable through all quantiles. A negative association is established between the defence burden (MGDP) and increases in income (GDP) although this does not necessarily mean a decline in the level of military spending but simple a negative association with its share in GDP. The negative sign of population (POP) may be indicating that larger population generates greater demand for civilian consumption than it does for defence needs.

Additionally, we must account for the unobserved heterogeneity across countries. A typical way to do this, is to implement fixed (FE) and random effects (RE) model formulations with the choice depending on the assumption adopted about the correlation among the cross-section specific error-component and the explanatory variables. To decide between FE or RE we applied a Hausman test where the null hypothesis is that the preferred model is RE versus the alternative the FE. ${ }^{7}$ It basically tests whether the unique errors are correlated with the regressors with the null hypothesis being that they are not. On the basis of the Hausman test, the RE model was rejected ( $p$ value $<0.05$ ) in favor of the FE model. The FE results are reported in Table 5, column 2. By and large, the findings accord with the results of the OLS estimation.

As already noted previously, a further step in the empirical investigation is to employ the semiparametric framework of quantile regression to test the robustness of the findings that the linear regression estimation yielded. If the explanatory power of the covariates varies with the observed magnitude of the response variable, interesting insights may be gained into the relationships under investigation. Table 5 summarizes the findings, with the supporting panels reporting the effect of the predictors at the 5th, 10th, 25th, 50th, 75th, 90th and 95th quantile of the MGDP distribution. Furthermore, Fig. 3 provides a graphical representation of the contribution of each predictor with the rest variables held constant. The vertical axis indicates the coefficient magnitude and the horizontal axis comprises the quantile scale. The black line starting from the origin joins the point estimates of the regression at each quantile. The red dashed line, running parallel to the horizontal axis, represents the OLS coefficient, hence, it remains constant at all levels. The variety of patterns which the former line adopts compared to the latter is indicative of the information foregone when we simply rely on mean tendency estimates from linear regression models.

The quantile estimation results justify the methodological choice not to solely rely on findings that stem from estimating only the conditional mean of the reaction variable. We cannot use criteria such as the AIC to select the model type. The quantile regression is recommended for analysis of data that are heterogeneous such that the tails and the central location of the conditional distributions vary differently with the covariates. The

See for instance chapter 9 in Greene (2008). 


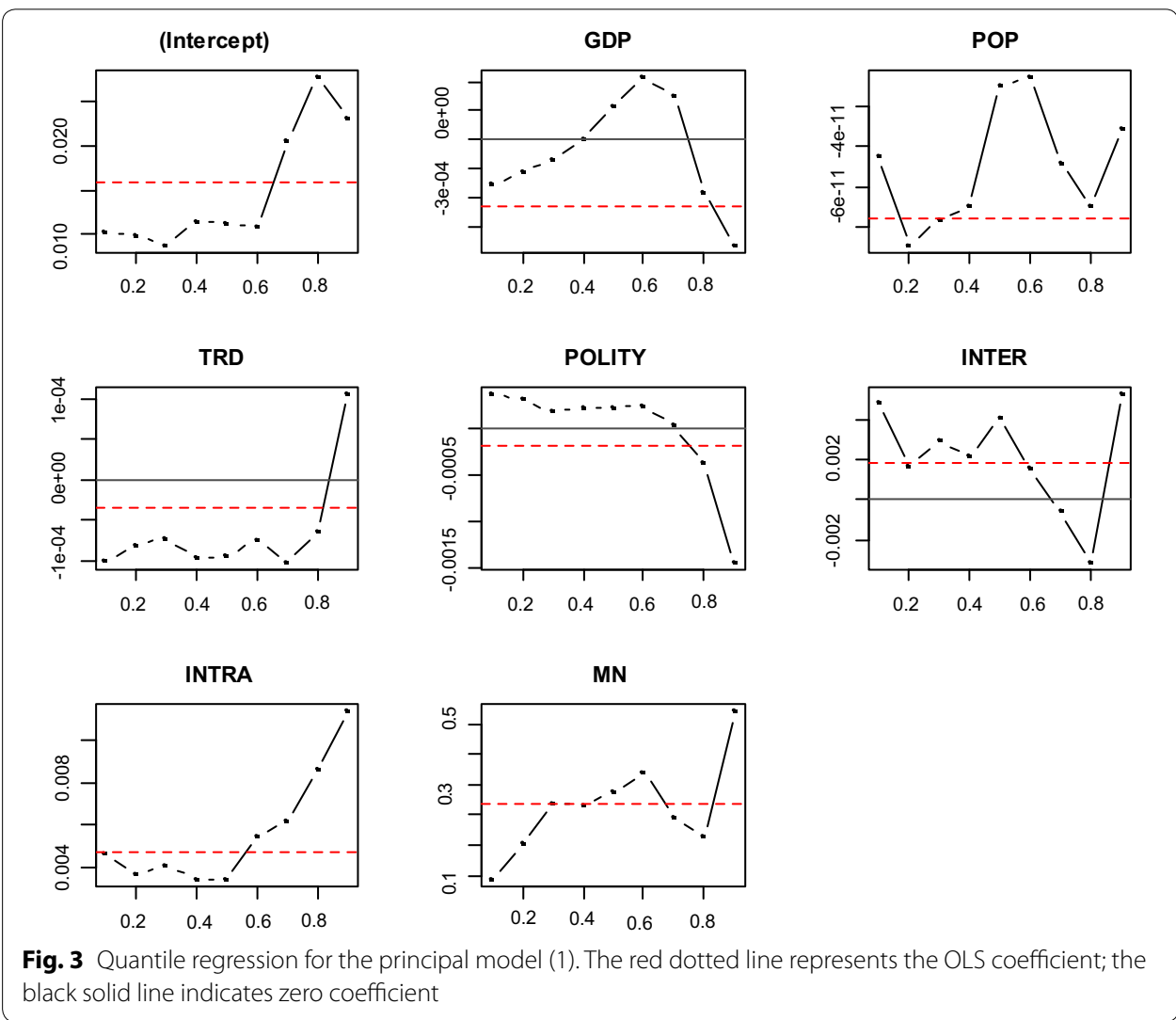

quantile regression provides a comprehensive view of the relationships between independent and dependent variables (i.e., not just centrally but also in the tails of the conditional distribution of the dependent variable. Koenker 2004).

As aforementioned, the effect of intrastate conflict (INTRA) and that of the Security Web (MN) remain positive and statistically significant throughout all quantiles albeit with a varying magnitude in the relevant coefficients (Table 5 and Fig. 3, respectively). On the other hand, interstate conflict (INTER) is significant until the 10th quantile and then becomes insignificant. Noteworthy is also the effect exerted by the Polity index (POLITY) introduced in the estimations to capture the regime effects on defence allocations. It appears flat for more than half of the MGDP distribution and steep for the rest. Also interesting to observe is the differences between the median and the tails in the case of GDP, which is significant in tails (5th, 10th, 90th and 95th quantile) and insignificant in median (25th, 50th and 75th quantile).

In Table 6 the findings of the model where the crime rate is included in the estimators are shown. Given the sample size and the time period for which the model is estimated ${ }^{8}$ the results are not directly comparable to those of Table 5 . Furthermore, since the period of the estimation is rather short (2003-15) no robust statistical inferences can be drawn. The crime variable exerts a statistically significant effect on defence spending, but the

\footnotetext{
${ }_{8}^{8}$ Due to crime statistics constraints, only six countries are included in this panel-El Salvador, Mexico, Colombia, Ecuador, Peru and Venezuela - and the period of the estimation is 2003-2015.
} 
Table 6 OLS and quantile regression results for model (2)

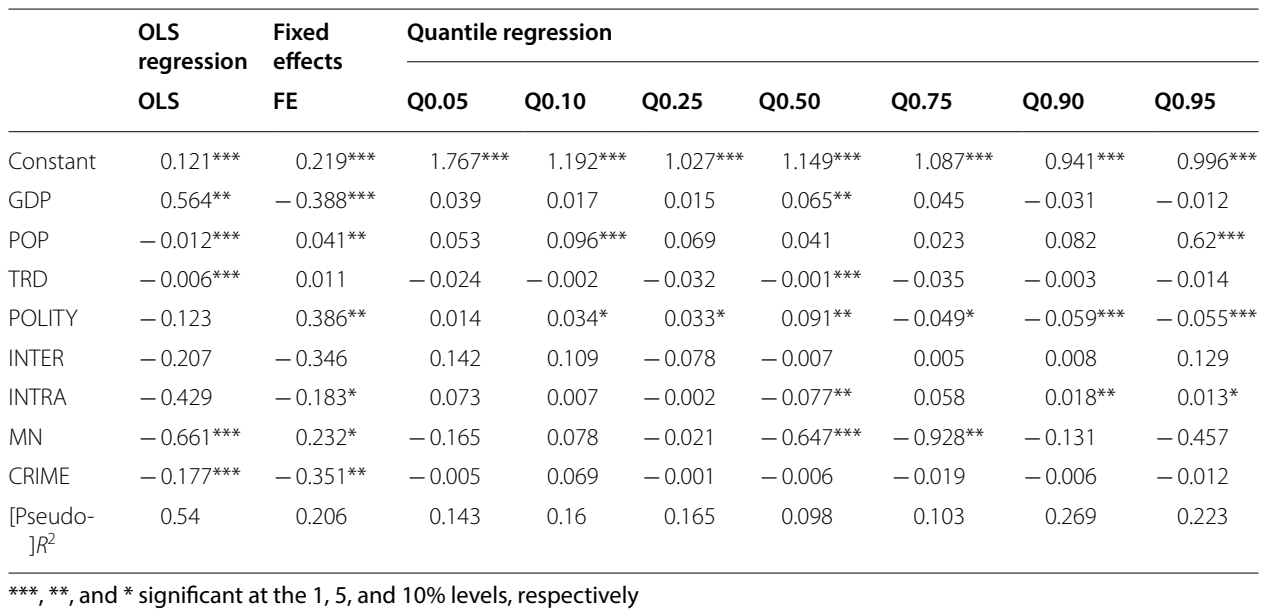

negative signed coefficient is a counterintuitive finding. ${ }^{9}$ Given that military spending is predominantly influenced by external security considerations or armed insurgencies, a plausible explanation for the negative sign of the crime coefficient is that it may be reflecting a process of a budgetary trade-off between defence spending and public order spending. Crime thwarting policies are primarily if not exclusively the mission of security forces such as the police that are financed through public order expenditures. Clearly, this is a tentative explanation that requires further empirical investigation.

Similar is the case with the intrastate (INTRA) coefficient in model (2) while noteworthy is the statistical insignificance of the interstate dummy (INTER). The findings for both interstate and intrastate conflict are not particularly surprising given the period for which model (2) is estimated. It is a period in which there is not interstate conflict in this sub-sample of countries and intrastate conflict is present only in Peru and Colombia (Shining Path and FARC \& ELN respectively), but appreciable less intense compared to previous periods. The GDP coefficient in the case of the FE results is negative which probably picks up the effect of declining defence burdens vis-à-vis the growth performance of the economies. Just as in the case of the results for model (1), a weakly positive coefficient is the case for the security web variable (MN).

As a final step in the empirical analysis of the determinants of military expenditure in the Latin American countries under investigation. GAMMs is recommended when a model contains non-linear effects since the interpretation of the marginal impact of a single variable (the partial derivative) does not depend on the values of the other variables in the model. Hence, by simply looking at the output of the model, we can make simple statements about the effects of the predictive variables that make sense to a nontechnical person. We can control the smoothness of the predictor functions to prevent overfitting and we don't have to know up front what type of functions we will need (Wood 2000, 2004, 2006a, b).

\footnotetext{
${ }^{9}$ Homicide rate per 100,000 population. Moreover, GAMMs are regularized models i.e., they have some level of built-in fortification against multicollinearity OLS does not. Hence, the OLS results are biased and safe conclusions can only be derived from the quantile regressions and the GAMM (Larsen 2015).
} 
Table 7 Additive regression effect of key covariates on MGDP for the principal model (1)

\begin{tabular}{lllcl}
\hline & Estimate & Std. Error & $\boldsymbol{t}$ value & $\boldsymbol{P r}(>|\boldsymbol{t}|)$ \\
\hline (Intercept) MGDP & 0.0185 & 0.0005 & 39.4150 & $<2 \mathrm{e}-16$ \\
INTER & 0.0009 & 0.0046 & 0.2000 & 0.8420 \\
INTRA & 0.0059 & 0.001146 & 5.139 & $3.67 \mathrm{E}-07$ \\
\hline Significance of smooth terms & EDF & $\boldsymbol{F}$ & $\boldsymbol{p}$ value \\
\hline GDP & 1.312 & 1.5610 & 2.5600 & 0.0583 \\
POP & 3.954 & 3.9970 & 25.7160 & $<2 \mathrm{e}-16$ \\
TRD & 2.337 & 2.8380 & 5.3090 & 0.0013 \\
POLITY & 3.9620 & 24.1020 & $<2 \mathrm{e}-16$ \\
MN & 3.762 & 3.825 & 19.897 & 0.0000 \\
\hline
\end{tabular}

Table 8 Additive regression effect of key covariates on MGDP for the crime rate model

\begin{tabular}{lllcl}
\hline & Estimate & Std. Error & $\boldsymbol{t}$ value & $\boldsymbol{P r}(>|\boldsymbol{t}|)$ \\
\hline (Intercept) MGDP & 0.7735 & 0.0322 & 24.0100 & $<2 \mathrm{e}-16$ \\
INTER & 0.0059 & 0.0176 & 1.345 & 0.21 \\
INTRA & 0.0235 & 0.0031 & 7.549 & 0.541 \\
\hline Significance of smooth terms & EDF & $\boldsymbol{F}$ & $\boldsymbol{p}$ value \\
\hline GDP & 2.988 & 3.4610 & 1.7690 & 0.0520 \\
POP & 3.887 & 3.9730 & 24.4530 & 0.0000 \\
TRD & 2.853 & 3.4000 & 2.4920 & 0.0648 \\
POLITY & 2.48030 & 10.9220 & 0.0000 \\
MN & 3.1960 & 3.638 & 4.185 & 0.0254 \\
CRIME & 1.8520 & 2.199 & 3.624 & 0.0287 \\
\hline
\end{tabular}

The upper part of Tables 7 and 8 shows the generalized regression results which, as it can be observed, coincide with the OLS estimates. The lower part reports the pairs of $F$-statistics and $p$ values along with the equivalent degrees of freedom (EDF) for each of the smooths. Thus and given this evidence, we reject the null hypothesis of a linear covariance between MGDP and its principal covariates. Moreover, the results confirm the non-linear behaviour (at the 1\% level). For some variables, the difference could be negligible, but for others, they are substantial, and non-linear. Notably, the positive estimate for crime, which indicate that the GAMMs methodology is able to overcome the negative sign from the OLS results.

Visual inspection in Fig. 4 confirms the non-linear effects. ${ }^{10}$ With MGDP on the vertical axis and the continuous predictors on the horizontal axis, the solid black curve passes through the mean values of the nonparametric regression coefficients. Key to the assessment of the effects is the surrounding gray area and the black marking density on the horizontal axis. The former represents a $95 \%$ confidence band. The black marking density is determined by the frequency of observations across the distribution of each of the predictors. Accordingly, our sample lends strong support to the estimated relationships. MGDP increases with population and MN, whereas it decreases with GDP

${ }^{10}$ Figure 4 refers to model 1 (Table 7). 

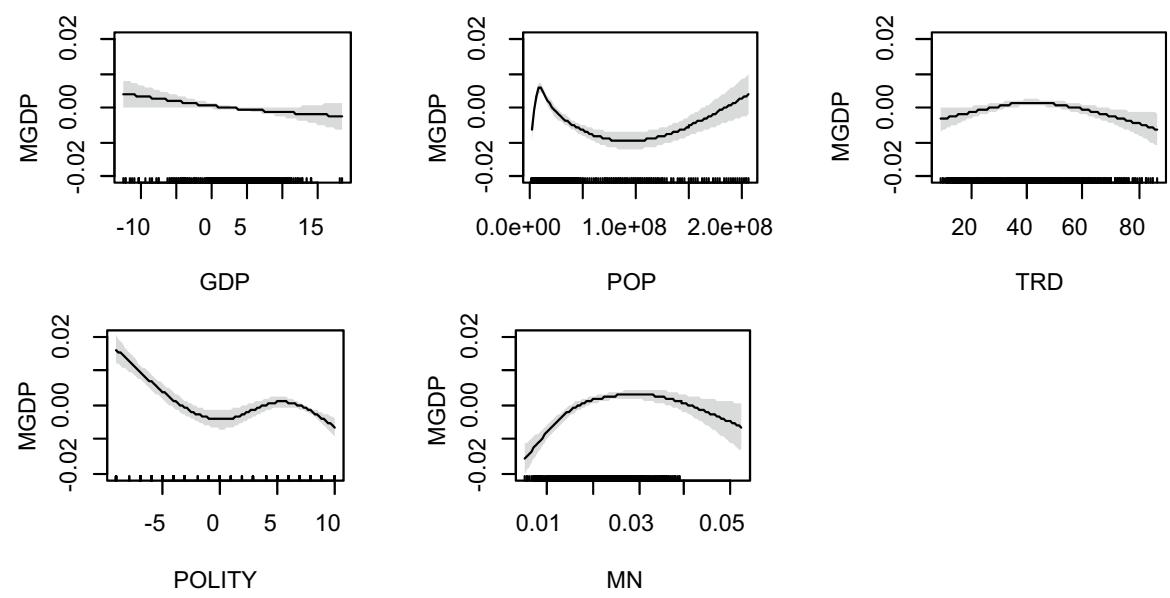

Fig. 4 Nonparametric additive regression for the principal model

and TRD; the thicker the marking density, the more discernible these effects become. In addition, POLITY an horizontal sigmoid type behaviour (decrease-increase-decrease), which is in line with the quantile results reported earlier. However, this is a joint outcome of low coefficient magnitudes and the logarithmic transformation of the variable. Overall, the maximum black marking density (the frequency of observations) in each graph coincides with the minimum surface of the gray area. Furthermore, the evaluated functions disclose the presence of non-linear effect among the MGDP and the selected regressors. Overall, it appears that the robustness of our findings is fairly strong thus, compared to a fully parametric framework, it allows for more reliable insights and inferences on the factors that drive the demand for military spending.

\section{Concluding remarks}

Several domestic and external factors affect the allocation of resources to defence. In particular, the relevant literature has identified a cohort of strategic, economic and political factors that drive defence expenditures. This paper set out to examine the determinants of the demand for military spending in the case of 12 Latin American countries: Dominican Republic, El Salvador, Guatemala, Mexico, Argentina, Bolivia, Brazil, Chile, Colombia, Ecuador, Peru and Venezuela. Using SIPRI's new extended data series the issue was examined for the period 1965-2015 using quantile regression that allows for better insights into the determinants of defence spending.

The results indicate that such public outlays have been driven by both domestic and external factors. The former include the economy as well as the political characteristics of the government as these are quantified by the Polity index of democracy. Intrastate state conflict that has afflicted many Latin American countries also emerged as a strong determinant along with the military spending by neighbouring countries with common borders that constitute the external security environment within which a country operates. Regarding the non-linear results, the quantile pattern findings for the principal model imply that the effect of intrastate conflict and that of the Security Web remain positive and statistically significant throughout all quantiles. On the other hand, intestate 
conflict is significant up to the 10th quantile and then its significance withers away. Notable is the non-linear effect exerted by the Polity index. In broad terms, it appears that allowing for non-linear effects of the various determinants of defence expenditures offers better insights on the complex relationship that drives resource allocations to the production of national defence.

\section{Authors' contributions}

All authors participated equally in writing the paper. All authors read and approved the final manuscript.

\section{Author details}

${ }^{1}$ Laboratory of Economic Policy \& Strategic Planning, Department of Economics, University of Thessaly, Volos, Greece.

${ }^{2}$ Department of Economics, Aristotle University of Thessaloniki, Thessaloníki, Greece.

\section{Acknowledgements}

The authors gratefully acknowledge the insightful comments and constructive suggestions of an anonymous referee that helped improve the paper. The usual disclaimer applies.

\section{Competing interests}

The authors declare that they have no competing interests.

\section{Publisher's Note}

Springer Nature remains neutral with regard to jurisdictional claims in published maps and institutional affiliations.

Received: 22 May 2017 Accepted: 23 July 2018

Published online: 05 October 2018

\section{References}

Abdelfattah Y, Abu-Qarn A, Dunne P, Zaher S (2014) The demand for military spending in Egypt. Def Peace Econ 25(3):231-245

Albalate D, Bel G, Elias F (2012) Institutional determinants of military spending. J Comp Econ 40:279-290

Arvanitidis P, Kollias C (2016) Converging defence burdens? Some further findings. Peace Econ Peace Sci Public Policy 22(4):365-375

Baayen RH, van Rij J, de Cat C, Wood SN (2016) Autocorrelated errors in experimental data in the language sciences: some solutions offered by generalized additive mixed models. arXiv preprint. arXiv:1601.02043

Biglaiser G (2002) Guardians of the Nation? Economists, generals, and economic reform in Latin America. University of Notre Dame Press, Notre Dame

Blanco L, Ruiz I (2013) The impact of crime and insecurity on trust in democracy and institutions. Am Econ Rev 103(3):284-288

Bove V, Brauner J (2016) The demand for military expenditure in authoritarian regimes. Def Peace Econ 27(5):609-625

Bove V, Nisticò R (2014) Military in politics and budgetary allocations. J Comp Econ 42:1065-1078

Catoggio MS (2011) Religious beliefs and actors in the legitimation of military dictatorships in the Southern Cone, 1964-1989. Latin Am Perspect 38(6):25-37

Cavatorta E, Smith R (2017) Factor models in panels with cross-sectional dependence: an application to the extended SIPRI military expenditure data. Def Peace Econ 28(4):437-456

Chernozhukov V, Imbens G, Newey W (2007) Instrumental variable estimation of non-separable models. J Econ 139(1):4-14

Christie E (2017) The demand for military expenditure in Europe: the role of fiscal space in the context of a resurgent Russia. Def Peace Econ. https://doi.org/10.1080/10242694.2017.1373542

d'Agostino G, Dunne JP, Pieroni L (2017) Does military spending matter for long-run growth? Def Peace Econ 28(4):429-436

Di Tella R, Edwards S, Schargrodsky E (eds) (2010) The economics of crime: lessons for and from Latin America. University of Chicago Press, Chicago

Dix R (1994) Military coups and military rule in Latin America. Armed Forces Soc 20(3):439-456

Douch M, Solomon B (2016) A dynamic panel analysis using SIPRI's extended military expenditure data: the case of middle power nations. Econ Peace Secur J 11(2):50-56

Dunne P, Perlo-Freeman S (2003) The demand for military expenditure in developing countries: a dynamic panel analysis. Def Peace Econ 14(6):461-474

Dunne JP, Tian N (2016) Military expenditure and economic growth, 1960-2014. Econ Peace Secur J 11(2):50-56

Dunne P, Nikolaidou E, Mylonidis N (2003) The demand for military spending in the peripheral economies of Europe. Def Peace Econ 14(6):447-460

Dunne JP, Perlo-Freeman S, Smith R (2008) The demand for military expenditure in developing countries: hostility versus capability. Def Peace Econ 19(4):293-302

Frantz E, Geddes B (2016) The legacy of dictatorship for democratic parties in Latin America. J Polit Latin Am 8(1):3-32 Greene W (2008) Econometric analysis, 6th edn. Prentice Hall, Upper Saddle River

Horowitz J, Lee S (2007) Nonparametric instrumental variables estimation of a quantile regression model. Econometrica 75:1191-1208 
Huang S, Throsby D (2011) Economic, political, and social determinants of peace. Econ Peace Secur J 6(2):5-14 Johnston J, DiNardo J (1997) Econometrics methods, 4th edn. McGraw-Hill, New York

Kauder B, Potrafke N (2016) The growth in military expenditure in Germany 1951-2011: did parties matter? Def Peace Econ 27(4):503-519

Klein T (2004) Military expenditure and economic growth: Peru 1970-1996. Def Peace Econ 15(3):275-288

Koenker R (2004) Quantile regression for longitudinal data. J Multivariate Anal 91(1):74-89

Koenker R, Bassett G (1978) Regression quantiles. Econometrica 46:33-50

Kollias C, Paleologou S-M (2017) The globalization and peace nexus: findings using two composite indices. Soc Indic Res 131:871-885

Kollias C, Paleologou S-M, Tzeremes P, Tzeremes N (2017) Defence expenditure and economic growth in Latin American countries: evidence from linear and nonlinear causality tests. Latin Am Econ Rev 26(2):2-25

Larsen K (2015) GAM: the predictive modeling silver bullet. Multithreaded. San Francisco, Stitch Fix, p 30

Looney R, Frederiksen P (1986) The future demand for military expenditure in Argentina. J Arms Control Disarmament 7(2):197-204

Looney R, Frederiksen P (1988) Economic determinants of Latin American defence expenditures. Armed Forces Soc 14(4):459-471

Malizard J (2016) Military expenditure and economic growth in the European Union: evidence from SIPRI's extended dataset. Econ of Peace Secur 11(2):37-44

Markowski S, Chand S, Wylie R (2017) Economic growth and demand for military expenditure in the Indo-Pacific Asia region. Def Peace Econ 28(4):473-490

Nikolaidou E (2008) The demand for military expenditure: evidence from the EU15 (1961-2005). Def Peace Econ 19(4):273-292

Norden D (1996) Redefining political-military relations in Latin America: issues of the new democratic era. Armed Forces Soc 22(3):419-440

Nordhaus W, Oneal J, Russett B (2012) The effects of the international security environment on national military expenditures: a multicountry study. Int Org 66(3):491-513

Paleologou S-M (2015) Modelling the demand for national security expenditure: a note. Def Peace Econ 26(4):457-464

Pamp O, Thurner P (2017) Trading arms and the demand for military expenditures: empirical explorations using new SIPRI-data. Def Peace Econ 28(4):457-472

Papaioannou E, Siourounis G (2008) Economic and social factors driving the third wave of democratization. J Comp Econ 36:365-387

Peláez A (2007) Defence spending and peacekeeping in Uruguay. Def Peace Econ 18(3):281-302

Perlo-Freeman S (2017) SIPRI's new long data-set on military expenditure: the successes and methodological pitfalls. Def Peace Econ 28(4):404-421

Perlo-Freeman S, Sköns E (2016) Snakes and ladders: the development and multiple reconstructions of the Stockholm International Peace Research Institute's military expenditure data. Econ Peace Secur 11(2):5-13

Ramos EM (2004) Country survey XIX: Mexico. Def Peace Econ 15(1):83-99

Richardson LF (1960) Arms and insecurity: a mathematical study of causes and origins of war. Boxwood Press, Pittsburgh Rosh RM (1988) Third world militarisation: security webs and the states they ensnare. J Confl Resolut 32(4):671-698 Sandler T, George J (2016) Military expenditure trends for 1960-2014 and what they reveal. Glob Policy 7(2):174-184

Seitz M, Tarasov A, Zakharenko R (2015) Trade costs, conflicts, and defense spending. J Int Econ 95:305-318

Smith R (1980) The demand for military expenditure. Econ J 90(360):811-820

Smith R (1989) Models of military expenditure. J Appl Econ 4(4):345-359

Smith R (1995) The demand for military expenditure. In: Hartley K, Sandler T (eds) Handbook of defence economics. North-Holland, Amsterdam, pp 69-87

Soares RR, Naritomi J (2010) Understanding high crime rates in Latin America. The role of social and policy factors. In: Di Tella R, Edwards S, Schargrodsky E (eds). The economics of crime: lessons for and from Latin America. University of Chicago Press, Chicago, pp 19-55.

Solarin S (2017) Determinants of military expenditure and the role of globalisation in a cross-country analysis. Def Peace Econ. https://doi.org/10.1080/10242694.2017.1309259

Vargas J (2012) The persistent Colombian conflict: subnational analysis of the duration of violence. Def Peace Econ 23(2):203-223

Wood SN (2000) Modelling and smoothing parameter estimation with multiple quadratic penalties. J R Stat Soc Series B (Stat Methodol) 62(2):413-428

Wood SN (2003) Thin plate regression splines. J R Stat Soc Series B (Stat Methodol) 65(1):95-114

Wood SN (2004) Stable and efficient multiple smoothing parameter estimation for generalized additive models. J Am Stat Assoc 99:673-686

Wood SN (2006a) Generalized additive models: an introduction in R. Chapman and Hall/CRC Texts in Statistical Science press, Boca Raton

Wood SN (2006b) Low-rank scale-invariant tensor product smooths for generalized additive mixed models. Biometrics 62(4):1025-1036

Wood SN, Scheipl F, Faraway J (2013) Straightforward intermediate rank tensor product smoothing in mixed models. Stat Comput 23(3):341-360

Yildirim J, Sezgin S (2005) Democracy and military expenditure: a cross-country evidence. Trans Stud Rev 12:93-100 